The Geneva Papers on Risk and Insurance, 22 (No. 85, October 1997) 571-590

\title{
Market Orientation and Business Performance in the Spanish Insurance Sector
}

\author{
by Nora Lado Coustré*, and Miguel Ángel Martínez Martínez**
}

\begin{abstract}
Market Orientation (MO) has taken a central role in discussions about strategic management and marketing (Day, 1992). And yet despite its importance, MO has been the subject of few theoretical and empirical studies (Kohli and Jaworski, 1990). The empirical study reported in this paper focuses on the relationship between the degree of market orientation and the business performance of insurance companies in Spain. The results of the study indicate that there is empirical support for the existence of a positive and significant relationship between a company's economic performance and its degree of market orientation.

As well as providing additional evidence, the results here reported constitute empirical support for, and an extension of, the concept of market orientation as given in the literature.
\end{abstract}

\section{Introduction}

Despite the importance of market orientation, only recently have researchers constructed a theory of the antecedents and consequences, developed a valid measure of the construct and tested its effect on business performance (Slater and Narver, 1994). Attention has recently been drawn to conceptualization of market orientation by the contribution of Kohli and Jaworski (1990). On the basis of a review of the literature and field interviews with managers, there authors formulated the following definition of the construct.

Market orientation has three components:

- organization-wide generation of market intelligence relevant to current and future customer needs;

- cross-departmental dissemination of the intelligence;

- organization-wide responsiveness to it.

Narver and Slater (1990) developed a definition of market orientation which closely parallels that of Kohli and Jaworski. Narver and Slater propose a measure which breaks the construct down into three behavioural components, all of them of crucial importance for the creation of sustainable superior value for customers. These three components are:

\footnotetext{
* Fundación Mapfre Estudios, Universidad Carlos III de Madrid (Spain).

** General Manager Fundación Mapfre Estudios, Universidad de Alcalá de Henares (Spain).
} 
- customer orientation: sufficient understanding of target buyers to enable the creation of permanent superior value for them;

- competitor orientation: understanding short-term strengths and weaknesses and longterm capabilities of both current and potential competitors;

- interfunctional coordination: involves coordination of the company's activities at interdepartmental level to deliver superior value to buyers.

Each of these three components involves the acquisition of intelligence, dissemination activities and managerial action. Narver and Slater developed a measure of market orientation and examined empirically the relationship between the degree of a business's market orientation and its profitability. Other significant empirical studies have examined the impact of market orientation on business performance (Jaworski and Kohli, 1993; Slater and Narver, 1994; Lambin, 1995).

On the basis of the Kohli/Jaworski and Narver/Slater models, Lambin (1995) and Rivera (1995) have developed a broader definition of market orientation. The concept itself is broader than the traditional concepts of customer of marketing orientation. Lambin and Rivera go a step further, proposing that market orientation is a competitive strategy involving all the participants in the market and all levels of the organization (Lambin, 1995).

The four market participants considered are:

- final customers;

- intermediate customers (distributors);

- competitors;

- macro-environment.

The basic hypothesis is that "market-oriented firms allocate human and material resources (a) to collect information about the expectations and behaviours of the different market participants. This information is then used (b) to design market-oriented action plans, which are implemented by involving all levels of the organization. Thus, to build a valid measure of market orientation two sets of indicators will be defined for each of the four market participants: analysis and action indicators, and one set of indicators for measuring the level of interfunctional coordination" (see Appendix 1).

In the present research we took as starting-point the model and scale tested into the insurance sector in Belgium by Lambin and Rivera, for implementation of the empirical study. The model was felt to be particularly suited to the characteristics of the Spanish insurance sector - above all in the explicit consideration that it gives to the importance of orientation for distributors. The purpose of this research was to verify the existence of a positive relationship between the degree of MO and the business performance of Spanish insurance companies. To this end, our first step was to purify the MO scale and make sure that it was sufficiently reliable and valid.

\section{Hypotheses}

The purpose of this research was to examine empirically the consequences of market orientation for business performance. A preliminary step was to ensure that the measure of MO used met standards of reliability and validity. Then, the first hypothesis was:

$\mathrm{H1}$ : The proposed measure of markets orientation is valid and reliable. 
a) The market orientation measure is reliable.

b) The market orientation measure possess content validity.

c) The market orientation measure possess criterion validity.

d) The market orientation measure possess construct validity.

A critical issue for practising managers and marketing academics is the relationship between market orientation and business performance (Reukert, 1992). As firms become more market-oriented, they will seek to understand customers' changing needs and attempt to satisfy these needs by modifying their total offerings while making a profit. Kohli and Jaworski (1990) proposed that in the long run, market orientation would lead to improved profits by creating superior value and strengthening customer loyalty. Preliminary support for their proposition came from Narver and Slater (1990), who identified a substantial positive relationship between market orientation and business unit profitability, on the basis of a sample of 140 business units from a single US corporation. We therefore propose that market orientation is positively related to long-run business performance.

H2: The greater the overall level of market orientation and the level of:

a) Analysis of the four market participants.

b) Strategic actions implementation targeting the four market participants.

c) Interfunctional coordination,

the higher will be the level of business performance in the long run.

\section{Empirical study}

These relationships were tested empirically in the closing months of 1994 . The field work was conducted using a survey questionnaire, which was sent to the General Managers of 104 insurance companies operating in the private insurance sector in Spain and having market shares larger than $0.05 \%$. The field study design envisaged two respondents from each company, the senior person responsible for marketing and one manager from another business function. The purpose of using two respondents was to obtain two independent measurements of the intensity of market orientation in each insurance company. It was also intended to confirm that MO is a strategy which involves the entire organization and hence can be usefully assessed by the heads of other functions besides marketing.

\subsection{Why the insurance sector was chosen}

This sector is of particular interest from the marketing viewpoint, as it works with intangible commodities in which service, quality and customer orientation are crucial elements. ${ }^{1}$ Moreover, here the conduct of business is strongly influenced by the added factor of the broker. We therefore chose a model of MO which would particularly suit this sector.

The insurance sector has traditionally operated subject to strict regulation and strongly protected from international competition. In Europe, for some years past now the Community authorities have been drawing up directives intended to remove restrictions and discrimination among companies, homogenize the requirements for setting up and carrying on an

1 At the World Insurance Congress in 1991, Hanway (see Greenwald, J., 1991) contended that insurers needed to be strongly market oriented in order to perform more efficiently. 
insurance business, and generally to liberalize the exercise of that business. Effective implementation of these directives has brought about a major increase in competition within the sector and has provoked major restructuring of insurance companies and groups.

The climate of competition in Europe is also being affected by the economic crisis and changes in the behaviour of customers, who are becoming increasingly demanding as regards the services they receive while exhibiting les loyalty. As a result of these developments, rivalry among competitors is on the increase, as is the importance of MO for the sector.

\section{Figure 1: Premiums as per cent of GDP in the European Union}

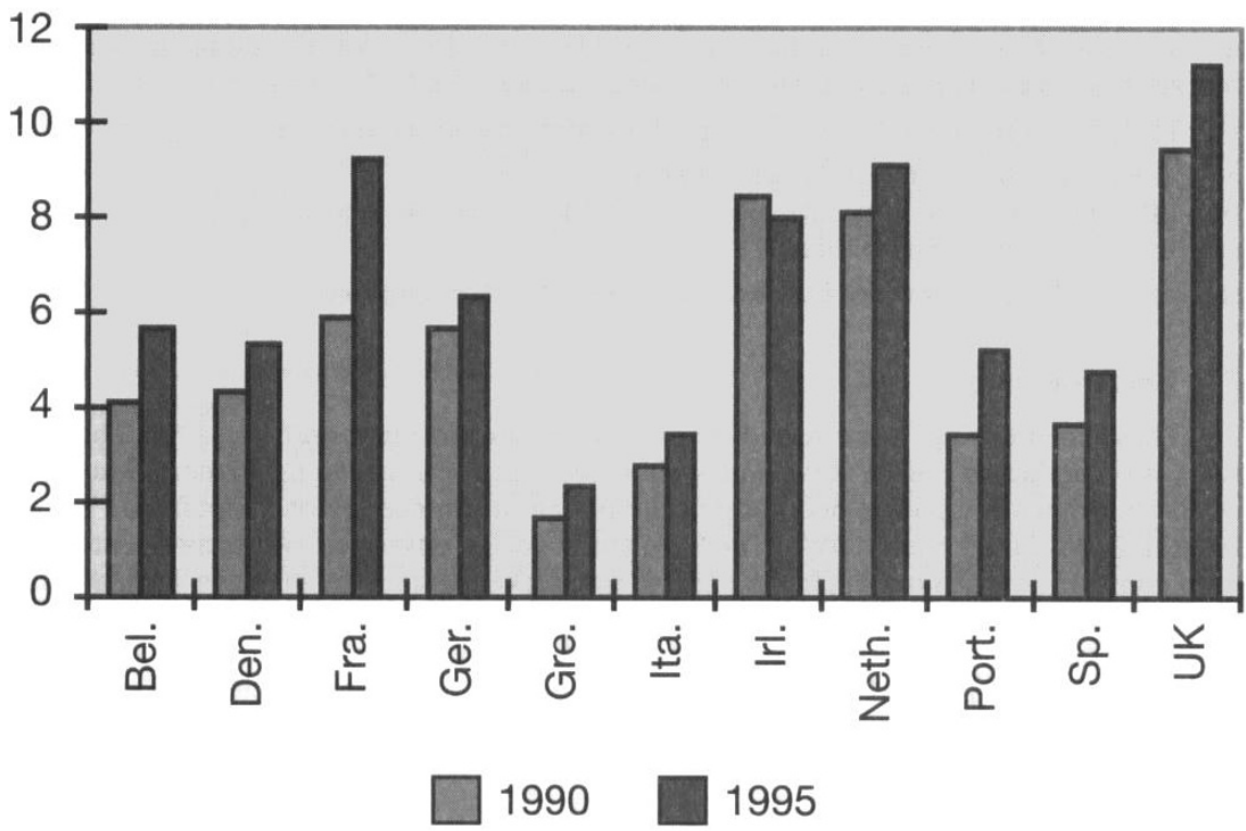

Regarding specifically the Spanish market, in $1995,4.8 \%$ of the GDP was devoted to insurance as compared to $7.1 \%$ for the Community as a whole (see Figure 1). There is therefore a lot of room for growth of the sector in Spain, particularly in life insurance. The graph also illustrates the growth in premiums as percent of GDP in the years 1990 to 1995. The data for 1996 confirm this upward trend, with premiums in Spain passing the 5.1\% GDP mark. ${ }^{2}$ This opportunity for growth is attracting foreign groups and as such constitutes a

2 It is worth noting that during 1994/95, growth figures for volume of premiums were distorted by externalization of funds devoted to covering employees' rights. This particularly affected figures for single-premium life policies. But in any case, even discounting the effect of single premiums on the total, the sector grew by an average of $8.6 \%$ for the year, with less increase in the last years. 
major challenge to domestic insurers. Against this background, the degree of orientation towards the customer, distributors, competition and the general socio-economic environment is becoming an increasingly important subject of study, not only for academics but for the business world as well.

\subsection{Questionnaire}

The questionnaire was modelled after one compiled in French by Lambin (1995) and Rivera (1995). In order to adapt it to the Spanish context, the questionnaire was first translated into Spanish then submitted to the opinion of an academic and expert in insurance, from which an initial version was prepared. Next, a pre-test was carried out with two experts from the insurance sector. With the results of these two pre-tests, the questionnaire was further adapted and improved, particular care being taken to ensure that questions were precise and would not occasion doubt or difficulties of interpretation. This second version of the questionnaire was pre-tested by means of a personal interview with three executives (a general manager, a marketing manager and a training manager) belonging to three different insurance firms.

\subsection{Objective measurement of results}

As regards the kind of indicators, it was decided to use objective data for informationgathering on measurement of results. Most previous studies on the relationship between market orientation and performance used subjective indicators, asking the respondents themselves to evaluate the results and the performance of their companies vis-à-vis the general run of the market. Objective indicators are preferable in that they are independent of either respondent or researcher.

The difficulty that we found was that available indicators of results encompass the whole of each insurance company, making no distinction between results corresponding to insurance of private individuals and those corresponding to insurance of businesses. Therefore, in the present study it is assumed that overall results for firms, as variables stand "proxy" for the results of mass insurance.

The specific measures of results used were:

- Net profits (NP)

- ROI, calculated as the ratio of net profit to investment

- Return on equity (ROE), calculated as the ratio of net profit to equity

- Total premiums acquired (PA)

- Growth (GRO), calculated as per cent annual increase in volume of acquired premiums.

The values for these indicators are taken from the balance sheets and annual accounts of insurance companies published by the Ministry of the Economy and Inland Revenue, Insurance Department, for the last three years. The first three indicators reflect the efficiency with which insurance companies achieve their profit and profitability targets. In fact they measure financial results. The last two indicators reflect market effectiveness, evaluating the company's commercial results. 


\subsection{The sample}

Of the 104 companies comprising the target population, two declined to answer the questionnaire because they were in the process of redefining their strategy, two because they were in the middle of a merger, and one gave no reason. From the other companies which did not reply, excepting 9 which agreed to cooperate but never returned the completed questionnaires, it was not possible to obtain a response.

In the end, 33 firms responded and 52 questionnaires were received. One of these was discarded because it was incomplete, so that the final count was 51 valid questionnaires from 32 insurance companies. Given that our aim was to get two questionnaires per firm, then with a target population of 104 firms, that means that the rate of response was $24.5 \%$, which is quite normal in postal surveys.

The 32 insurance companies comprising the actual sample attained an aggregate total of over 915,000 million pesetas in premiums in 1993, representing approximately $35 \%$ of the total Spanish sector for that year.

Table 1, which appears further below, shows the distribution of the target population and the actual sample in terms of company size as measured by volume of premiums acquired.

If we examine the representativeness of the sample in terms of average size with respect to premium volumes, the China-squared test reveals no significant differences between sample distribution and target population distribution. From which we may conclude that the sample is representative of the population as regards distribution by premium volume.

Table 1:

Structure of target population and sample in terms of volume of premiums (million pesetas)

\begin{tabular}{|c|c|c|c|c|}
\hline \multirow{2}{*}{$\begin{array}{c}\text { Premium } \\
\text { volume }\end{array}$} & \multicolumn{2}{|c|}{ Target population } & \multicolumn{2}{|c|}{ Sample } \\
\cline { 2 - 5 } & $\begin{array}{c}\text { No. of } \\
\text { firms }\end{array}$ & $\begin{array}{c}\text { \% of } \\
\text { total }\end{array}$ & $\begin{array}{c}\text { No. of } \\
\text { firms }\end{array}$ & $\begin{array}{c}\% \text { of } \\
\text { total }\end{array}$ \\
\hline 40,000 or over & 17 & 16.3 & 5 & 15.6 \\
from 39,999 to 20,000 & 17 & 16.3 & 11 & 34.4 \\
from 19,999 to 5,000 & 46 & 44.3 & 9 & 28.1 \\
4,999 or less & 24 & 23.1 & 7 & 21.9 \\
\hline Total & 104 & 100 & 32 & 100 \\
\hline
\end{tabular}

Source: Unespa

Postal questionnaires have been criticized as liable to bias arising from non-respondents, making it impossible to generalize about the entire population. In order to detect any problems with non-respondents, we used techniques of extrapolation. The questionnaires received were divided into quartiles on the basis of reception data. The first quartile contained the questionnaires received earliest and the fourth quartile those received latest. Persons responding later were assumed to be similar to those not responding (Armstrong, $\mathrm{J}$. and Overton, T., 1977). T-tests between cases in the first and fourth quartiles indicated no significant differences in means of MO measurements. 


\section{Reliability assessment and purification of the market orientation scale}

\subsection{General analysis of reliability}

If any scale is to be valid and of practical use, it must be reliable. In conceptual terms, the raliability of a scale is defined as: the degree to which measurements are error-free and provide consistent empirical results.

For our study of the reliability of the market orientation scale and each of the subscales used to measure its components, their respective Alpha Cronbach coefficients were calculated and the correlations of each item with the total scale analysed.

Analysis of the results for reliability of the scale showed the following:

1) The market orientation scale presents a very high level of reliability: Alpha Cronbach 0.96 , well above the minimum of 0.7 recommended as acceptable for exploratory investigations by Nunnally (1978). It is also well above the average Alpha Cronbach coefficient $(0.77)$ reported in articles published over the last three decades ( $R$. Peterson, 1994). The same is true of the reliability of the all the analysis and action scales for the components of MO: customer orientation, competitors orientation, distributor orientation, environment orientation and coordination among the different business functions. The level of reliability exceeds the level recommended for applied research (0.9-0.95) and therefore the scale may be considered suitable for that purpose. The level of reliability of the scale is, then, quite satisfactory.

2) If we examine the coefficient of item-total correlation, we find that the great majority of items correlate strongly with the entire scale, except for 6 items having correlations of less than 0.26 . In order to maximize the Alpha coefficient and then carry out the relevant tests, it was decided to remove these 6 items from the scale.

\subsection{Analysis of reliability of each sub-scale}

This study followed the approach developed by Nunnally (1978) to evaluate the allocation of each item to each of the sub-scales measuring the components of Market Orientation. The basic idea was that each item should be strongly correlated with the scale as a whole. But in addition, each item ought to correlate even more strongly with the whole of the sub-scale corresponding to the MO component in which it was included than with other subscales corresponding to other components.

A look at the correlation of each item with the scale component in which it was included shows that of the 68 items comprising the original scale, only 6 (not counting the items eliminated in the previous phase) correlated more strongly with a component other than the one to which it had initially been allocated.

Before deciding to reallocate, each one was analysed to see whether it could justifiably be included in another component. For example, variables AA12 (commercialization of innovative products) and AA17 (development of a marketing plan to coordinate action), originally allocated to Final Customer Orientation, correlated more strongly with Competitor Orientation and Interfunctional Coordination respectively. This was something that could be accepted in theory. The correlations of each item with respect to the five sub-scales were recalculated and it was found that each of the items in fact correlated more strongly with its allocated component that with the others.

The final results of analysis of the scale's reliability are shown in table 2 . 
Table 2: Reliability of the market orientation scale

Number of cases: 51

Number of items: 62

Scale from 0 to 10

\begin{tabular}{|c|c|c|c|}
\hline M.O. component & $\begin{array}{c}\text { Alpha } \\
\text { Cronbach }\end{array}$ & Average & $\begin{array}{c}\text { Standard } \\
\text { deviation }\end{array}$ \\
\hline Final customer orientation & 0.9056 & 5.720 & 1.510 \\
\hline Analysis & 0.8934 & 5.320 & 1.774 \\
\hline Actions & 0.8258 & 6.120 & 1.598 \\
\hline Distributor orientation & 0.9135 & 6.937 & 1.528 \\
\hline Analysis & 0.8623 & 6.781 & 1.536 \\
\hline Actions & 0.8708 & 7.044 & 1.677 \\
\hline Competitor orientation & 0.8842 & 5.894 & 1.522 \\
\hline Analysis & 0.8659 & 5.869 & 1.714 \\
\hline Actions & 0.8066 & 5.765 & 1.700 \\
\hline Environment orientation & 0.8661 & 4.694 & 1.976 \\
\hline Analysis & 0.9359 & 5.402 & 2.336 \\
\hline Actions & 0.7896 & 3.987 & 2.354 \\
\hline Interfunctional coordination & 0.9029 & 5.824 & 1.743 \\
\hline Analysis of market & 0.9358 & 5.540 & 1.636 \\
\hline Action on markets & 0.9163 & 5.780 & 1.439 \\
\hline $\begin{array}{c}\text { Global scale of } \\
\text { market orientation }\end{array}$ & 0.9656 & 5.814 & 1.391 \\
\hline
\end{tabular}

\subsection{Assessment validity of the market orientation scale}

The validity of a measure is as great as the capacity of the scale to really measure what it is intended to measure. According to Nunnally, there are different types of validity.

\subsubsection{Content validity}

A scale may be said to possess validity of content if there is a certain unanimity of opinion as to whether or not the items comprising the scale cover all aspects of the variable to be measured.

The questionnaire pre-test and the academic opinions indicated that the items selected adequately represented scale content. A further indicator of content validity was the small percentage of times that an item was considered not pertinent by respondents (out of 61 items and 52 questionnaires, only $1 \%$ were marked "not appropriate" or "not pertinent").

\subsubsection{Criterion validity}

This kind of validity, also referred to as external validity, includes predictive and concurrent validity. The Alpha Cronbach coefficient arrived at in evaluation of scale reliability was 
also sufficiently high to assure its criterion validity. Correlation between $\mathrm{MO}$ measurement and measurements of performance indicated that the predictivity of the scale was valid.

\subsubsection{Construct validity}

This third kind of validity refers to the suitability of the scale for the purpose of operationalizing the theoretical construct and measuring it. Establishing the construct validity entailed a study of the convergent validity and the discriminatory validity of the scale.

\subsubsection{Convergent validity}

The high and very significant positive correlations shown in Table 3 between scale components is clear evidence that all the components converge towards a single underlying construct. Also, the Alpha Cronbach coefficient (0.96) and the results of factor analysis further corroborate the convergent validity of the scale. An analysis of principal components shows that two factors account for virtually $70 \%$ of total variance in the scale.

\subsubsection{Discriminant validity}

Our aim was to prove that the scale is capable of empirically differentiating the construct we wish to measure from other different but closely related constructs.

The discriminant validity of the construct is evident if we examine the level of correlation of the Market Orientation scale with a scale which measures the emphasis placed by the company on innovation (Alpha Cronbach 0.84) vis-à-vis the correlation of the Market Orientation scale with a scale that measures the importance the company attaches to a lowcost strategy (Alpha Cronbach 0.80).

Table 3: Correlations between MO components

\begin{tabular}{|l|c|c|c|c|c|c|}
\hline \multicolumn{7}{|c|}{ Correlation coefficients } \\
\hline & MO & OFC & ODIST & OCOMP & OENV & COORD \\
\hline OF & 1.0000 & & & & & \\
ODIST & $.8933^{* *}$ & 1.0000 & & & & \\
OCOMP & $.7142^{* *}$ & $.6451^{* *}$ & 1.0000 & & & \\
OENV & $.8083^{* *}$ & $.6859^{* *}$ & $.5818^{* *}$ & 1.0000 & & \\
COORD & $.8580^{* *}$ & $.7316^{* *}$ & $.5664^{* *}$ & $.6884^{* *}$ & 1.0000 & \\
\hline
\end{tabular}

* Signif. Lev.: $0.05 \quad{ }^{* *}$ Signif. Lev. : $0.01 \quad$ (1-tailed)

OFC $=$ Final Customer Orientation OENV $=$ Environment Orientation

ODIST $=$ Distributor Orientation COORD $=$ Interfunctional Coordination

OCOMP = Competitor Orientation

MO entails outward orientation of the company - the will to monitor changes in the environment in order to respond to these with strategic actions. MO is therefore conceptually allied with innovation and less closely related to a low-cost strategy, which indicates an inward orientation. 
The correlation between market orientation and innovation is stronger than the correlation between market orientation and low-cost strategy, which is indicative of the discriminatory validity of the scale.

Table 4 shows the pattern of correlations between Market Orientation and scales of Innovation and Low Costs.

Table 4: Correlations between $M O$ and scales of innovation and low costs

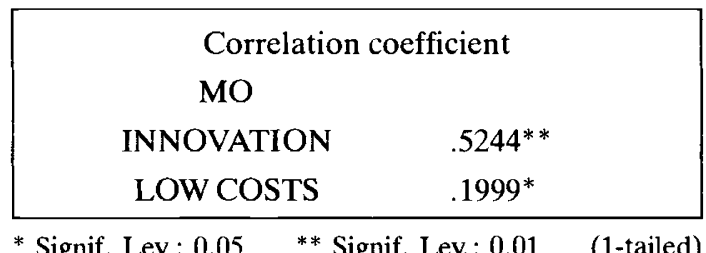

We may therefore conclude that the scale used is reliable and valid as an instrument for measuring the intensity with which companies adopt a market orientation.

\section{Results of measurement of market orientation}

First of all we analysed the average scores for each of the questions in the questionnaire which refer to the variables considered for measurement of MO. This was the first microlevel analysis.

In a second section following this one, we present a macro-analysis and we discuss the results of the calculation of mean overall level of $\mathrm{MO}$ and its components.

\subsection{Results for each of the items comprising $M O$}

\subsubsection{Items on customer orientation}

From the average scores in questions referring to degree of analysis and strategic action on final customers, it is clear that in general the averages for variables relating to "strategic action" were higher than those for "analysis". On average, the scores for questions on the degree of effort companies put into analysis and understanding of the evolution of current and potential customers' needs, preferences and behaviour patterns were medium to low. This may indicate that strategic actions targeting customers are not subjected to sufficient analysis nor backed up by systematic market research. We also found that the lowest scores $\ddot{A}$ those under 5 on a scale of 0 to $10 \ddot{A}$ were for 4 "analysis" variables. The variables of this kind on which the insurance companies were weak are:

A1 Permanent measurement of degree of customer satisfaction.

A7 Complete and up-to-date information for monitoring of product image.

A8 Possession of a system for measuring the profitability generated by each customer.

A9 Complete and up-to-date information for monitoring the evolution of customer preferences as to product characteristics.

B9 Possession of a system for ascertaining customer opinion on the firm's distributors. 
It would seem from these results that Spanish insurance companies' marketing information system could do with improvement in terms of providing systematic information on the evolution of degree of customer satisfaction and customer preferences, and on product image.

Moreover, variable A8 indicates that the design of the accounting systems used by many firms is inward-oriented, essentially towards products, without any eye for the market. If there is no information available on profitability per customer, it will not be possible to properly and efficiently develop customer management and individualized attention. It should be noted that this variable was not taken into account in calculating the overall MO measurement, having been removed from the scale in view of its low correlation with the rest of it. We believe that the reason for this low correlation lies in the fact that insurers either have a system for measuring the profitability generated by each customer or they do not have one. This variable is not as easily graduated as others in the scale so that standard deviation is very high. In any event, the results for all variables were included in this section of the analysis, even where they were not subsequently taken into account for calculation of the MO measurement, because they provide valuable information on the general state and level of marketing in these companies.

The highest average scores (over 7) among customer orientation variables were for the following:

AA14 Rapid response to customer complaints.

AA22 Abandonment of market segments which threaten the firm's profitability.

\subsubsection{Items on distributor orientation}

Average scores for questions on distributor orientation were higher than for questions on customer orientation. Average scores of over 7 were found for the following variables:

B3 Knowledge of distributors' objectives, means and constraints. ${ }^{3}$

B4 Analysis of compatibility of marketing strategy with distributors' objectives.

B5 Understanding of the problems that commercialization of products may involve for distributors.

B7 Possession of a system for calculating the profitability generated by each distributor.

BB12 Company's commitment to contact with distributors.

BB13 Treatment of distributors as if they were customers.

BB14 Information to distributors on marketing strategy.

BB15 Training of distributors (highest score of all variables in the scale).

The level of distributors orientation among insurance companies was high, particularly as regards training and familiarity with them. Where scores were relatively not so high (less than 6) was in soliciting distributors' opinions before launching a new product and modification of product characteristics to adapt to distributors' needs.

\footnotetext{
${ }^{3}$ This was the variable for which dispersal of responses was smallest.
} 


\subsubsection{Items on competitor orientation}

Of the variables on Competitor Orientation, none produced an average score of above 7. Scores in general were rather low. The two questions with the lowest average scores were:

C3 System for good identification of competitors' strong and weak points.

CC10 Utilization of benchmarking.

\subsubsection{Items on environment orientation}

The answers to questions on Environment Orientation scored even lower on average than those on competitor orientation. The average score for the proposal on development of crisis management procedures to cope with unforeseen events was 2.98 , and for the question on consideration of the ecological factor in designing strategy, it was 2.04 . In all variables of the "action on the environment" sub-scale, average scores were less than 5 .

It was also found that the average scores were higher for variables on analysis of the environment than for action on the environment.

\subsubsection{Items on interfunctional coordination}

The items marked lowest in this component of MO were:

E10 Consideration of indicators of contribution to customer satisfaction in personnel incentive systems.

E6 Introduction of procedures enabling each function to receive information on its contribution to customer satisfaction.

E7 Encouragement of direct contact with customers by all levels and functions of the organization.

The only item for which the average score was above 7 was:

E9 Messages conveyed by advertising, promotion and public relations are coordinated in order to give a coherent image of the company.

\subsection{Results on overall intensity of $M O$}

As Table 2 shows, average market orientation of the companies in the sample was 5.81 on a scale of 0 to 10 . The most market-oriented company scored 8.56 and the least 2.81 .

These closely resemble the results reported by Lambin-Rivera. J.J. Lambin's statement (1995) that: "...the average score is very modest when compared to an earlier survey on the consumer goods sector, where the mean was $7.5 .{ }^{4}$ There is therefore no sign here of any bias towards self-indulgence, which is always a risk in self-assessment surveys".

This true of the present case. Again in line with the Belgian findings, in the present case the lowest scores were for environment orientation, more specifically "action on the environment". These results bear out J.J. Lambin's 1995 remark that insurance companies appear to be chiefly broker-oriented. This highlights the step forward represented by this MO model with respect to its forerunners, which gave no explicit consideration to distributor orientation

\footnotetext{
${ }^{4}$ Research undertaken by J. Llonch on firms in a variety of industrial sectors in Catalonia, the average score for Market Orientation was 4.91 on a scale of 1 to 7 , equivalent to 6.51 on a 10 -point scale.
} 
as a factor. In this case, if only conventional consumer orientation had been measured, the model would not have reflected the importance attached by firms to analysis and strategic action oriented towards brokers.

Again it was found that the average degree of "analysis of final customers" was lower than that of "strategic action on the final customer". This difference is highly significant statistically (t-test of difference, for a confidence interval of $95 \%$, was 3.88 , sig. 0.000 and Wilcoxon tests, 2-tailed, $Z=3.6393$, sig. 0.0003). For customer orientation, in 37 cases out of 51 "analysis" scores higher than "action". As we noted earlier, these results would indicate that the effort put into adoption of actions and measures to cope with customers' needs is not mirrored by a similar effort to analyse these needs.

Analysis of how MO was evaluated by respondents who were marketing managers and respondents in different positions in the same firm showed no significant differences between the two viewpoints. This bears out our contention that MO is a strategy for the entire organization. It does not involve only the marketing department and is evaluated in a similar way by marketing and non-marketing managers alike.

\section{Relationship between Market Orientation and Performance}

The effect on performance of adopting a pronounced market orientation is a key issue for marketing. If market orientation does not entail positive effects for the company, then the ultimate justification for marketing collapses. As we have noted, however, there is insufficient empirical evidence on this.

We have also seen that according to exploratory research by Kohli and Jaworski (1990) and an empirical survey carried out by Reukert (1992), MO does have beneficial effects on the company's results. In the present study we confined ourselves to examining the relationship between MO and the company's economic results.

To analyse the relationship between MO and measurements of results, the first step was a "face value" analysis, followed by analysis of correlations and multiple regressions. The results of these anaylses were as follows.

The first step in analysing this subject was to compare the measurements of average results for the group of companies with the highest $\mathrm{MO}$ level and the same measurements for companies with the lowest MO level.

Table 5 compares the economic results achieved by the group with a MO rating of over 6.84 and the group with a MO rating of less than 5.17. From this table we can see that in almost all performance indicators, average values were higher for the 13 firms with the highest MO rating than for the firms which were least market-oriented.

The t-test shows that the difference between the average performance of firms with a high and a low level of market orientation is positive and significant for 11 of the 12 results indicators considered.

These initial findings support the hypothesis that where the level of MO is higher, financial and commercial results are better. To corroborate this hypothesis, we went on next to analyse the correlations between the selected indicators of economic results and scores on the market orientation scale. 
Table 5:

Differences in performance of companies with high $M O$ and companies with low $M O$

\begin{tabular}{|c|c|c|c|c|}
\hline \multirow{2}{*}{$\begin{array}{c}\text { Measurement } \\
\text { of results for the last three } \\
\text { years (average) }\left(^{*}\right)\end{array}$} & \multicolumn{2}{|c|}{$\begin{array}{c}\text { Level of market } \\
\text { orientation }\end{array}$} & \multirow{2}{*}{$\mathrm{t}$ test } & \multirow{2}{*}{ sig. of $\mathrm{t}$} \\
\cline { 2 - 3 } & $\mathrm{n}=13$ & $\mathrm{n}=13$ & & \\
\hline ROI93 & 3.3 & -2.0 & 1.89 & 0.07 \\
NP93 & 1,926 & 94 & 3.41 & 0.02 \\
PA93 & 33,269 & 16,863 & 2.12 & 0.04 \\
ROE93 & 21.20 & 3.59 & 3.16 & 0.00 \\
& & & & \\
ROI92 & 4.49 & -3.90 & 1.85 & 0.08 \\
NP92 & 1,455 & -58 & 3.90 & 0.00 \\
PA92 & 37,608 & 9,768 & 2.84 & 0.01 \\
ROE92 & 25.71 & -6.94 & 2.82 & 0.01 \\
& & & & \\
ROI91 & 3.68 & -0.45 & 1.89 & 0.07 \\
NP91 & 1,070 & 87 & 2.43 & 0.02 \\
PA91 & 23,993 & 7,098 & 3.66 & 0.00 \\
ROE91 & 0.75 & 2.32 & N/S & \\
\hline
\end{tabular}

$\mathrm{NP}=$ Net profits $\mathrm{PA}=$ Premiums acquired $; \mathrm{ROE}=$ return on equity

$\left({ }^{*}\right)$ Source: Balance Sheets and Annual Accounts published by the Department of Insurance. Ministry of the Economy.

The results (see Table 6) show that in all three years, ROI, Return on Equity, Net Profits and Premiums Acquired correlated positively and significantly - in most cases very significantly - with the measured intensity of the companies' Market Orientation. results.

Thus, we have clear confirmation of a positive relationship between MO and company

The correlation with annual premium growth, on the other hand, is negative and not significant. A similar finding was reported by Lambin and Rivera, who concluded that their results did not support the contention that market orientation has a short-term effect on performance. The results from Spain bear out this conclusion.

As to the effect on indicators of economic results of orientation towards the final customer, distributors, competition and environment and interfunctional coordination, the conclusions are the same as for market orientation overall. It has already been noted that all components were strongly correlated, and this now serves to reaffirm the validity of the model. All the components had a positive effect on economic results.

Going into more detail, Table 7 shows the correlations of the nine components of market orientation with indicators of results for 1993. Note that the weakest correlations were for "action on final customer" and "action on competion". However, with the exception of per cent annual increase in premiums, all correlations were positive and a good majority were highly significant. 
Table 6: Correlations between $M O$ and its components, and indicators of performance for the last three years

51 cases

\begin{tabular}{|l|l|l|l|l|l|c|}
\hline & MO & OFC & ODIST & OCOMP & OENV & COORD \\
\hline ROI93 & $.3772^{* *}$ & $.3196^{*}$ & $.3990^{* *}$ & $.3067^{*}$ & $.2909^{*}$ & $.3587^{* *}$ \\
NP93 & $.4612^{* *}$ & $.4181^{* *}$ & $.4338^{* *}$ & $.3954^{* *}$ & $.3342^{*}$ & $.4276^{* *}$ \\
PA93 & $.3278^{*}$ & $.3339^{*}$ & $.3301^{*}$ & .2585 & .2692 & $.2772^{*}$ \\
ROE93 & $.4282^{* *}$ & $.4067^{* *}$ & $.4158^{* *}$ & $.2816^{* *}$ & $.3578^{* *}$ & $.4054^{* *}$ \\
GRO93 & -.1513 & -.1014 & .0452 & -.2477 & -.2461 & .0025 \\
& & & & & & .2521 \\
ROI92 & .2631 & .2236 & .1930 & .2261 & .2521 & .2095 \\
NP92 & .1451 & .0657 & .1316 & .2017 & .2620 & .0165 \\
PA92 & $.3979^{* *}$ & $.3975^{* *}$ & $.3626^{* *}$ & .2393 & $.4124^{* *}$ & $.3258^{*}$ \\
ROE92 & $.3912^{* *}$ & $.3193^{*}$ & $.2781^{*}$ & $.3379^{*}$ & $.3841^{* *}$ & $.3108^{*}$ \\
GRO92 & -.1974 & -.1787 & $-.3139^{*}$ & -.2181 & -.1583 & -.1445 \\
& & & & & & \\
ROI91 & $.2822^{*}$ & .2146 & .1279 & .1809 & .1703 & $.3410^{*}$ \\
NP91 & $.2851^{*}$ & .1833 & .2075 & .2424 & .1315 & $.3539^{*}$ \\
PA91 & $.4235^{* *}$ & $.4058^{* *}$ & $.2994^{*}$ & $.4461^{* *}$ & $.4059^{* *}$ & .2669 \\
ROE91 & .0125 & -.0208 & -.0486 & -.0219 & -.0532 & .0886 \\
\hline
\end{tabular}

* Signif. Lev. $0.05 \quad{ }^{* *}$ Signif. Lev. $0.01 \quad$ (1-tailed)

NP $=$ Net Profits; PA $=$ Premiums Acquired $;$ ROE $=$ Return on Equity

Table 7: Correlations between the different components of $M O$ indicators of results

\begin{tabular}{|l|l|l|l|l|c|}
\hline \multicolumn{7}{|c|}{ Correlation coefficients } \\
\hline & ROI93 & NP93 & PA93 & ROE93 & GRO93 \\
\hline ANFC & .2272 & $.4511^{* *}$ & $.3355^{* *}$ & $.3551^{* *}$ & -.1947 \\
ANDIS & $.3942^{* *}$ & $.3848^{* *}$ & $.2688^{*}$ & $.4605^{* *}$ & .0378 \\
ANCOMP & $.2607^{*}$ & $.4772^{* *}$ & $.2972^{*}$ & $.3217^{*}$ & $-.2977^{*}$ \\
ANAENV & $.3289^{* *}$ & $.3616^{* *}$ & .2136 & $.4153^{* *}$ & $-.2508^{*}$ \\
ACTFC & $.2850^{*}$ & $.2813^{*}$ & $.2801^{*}$ & $.3208^{*}$ & .0628 \\
ACTDIS & $.4069^{* *}$ & $.3815^{* *}$ & $.2832^{*}$ & $.3556^{* *}$ & .0759 \\
ACTCOMP & .2318 & $.2339^{*}$ & .1259 & .1852 & -.1977 \\
ACTENV & $.3324^{* *}$ & $.3146^{*}$ & $.3529^{* *}$ & $.2727^{*}$ & -.1155 \\
COORD & $.3695^{* *}$ & $.4133^{* *}$ & $.2777^{*}$ & $.4114^{* *}$ & .0239 \\
\hline
\end{tabular}

* Signif. Lev. $0.05 \quad{ }^{* *}$ Signif. Lev.0.01 (1-tailed)

ANFC $=$ Final customers analysis; ANDIS $=$ Distributors analysis;

ANCOMP = Competitors analysis; ANAENV = Environment analysis $;$ ACTFC $=$ Final customers actions; ACTDIS $=$ Distributors actions; ACTCOMP $=$ Competitors actions;

$\mathrm{ACTENV}=$ Environment actions $;$ COORD $=$ Interfunctional coordination 
All the results are congruent, so that it can be fairly said that the companies which placed most emphasis on market orientation as defined and measured in the chosen MO model, exhibited better economic and commercial performance.

Nevertheless, the doubt remained whether it might not simply be size that causes the positive correlation of MO with results. Analysis of partial correlations showed that this is not the case. However, for reasons of space, analysis is confined here to economic results for 1993. Size is measured in terms of premium volume. As Table 8 shows, the partial correlations between $\mathrm{MO}$ and results indicators are positive and significant regardless of the indirect effect of the size factor.

Table 8: Partial correlation $M O$ - performance with allowance for the size factor

\begin{tabular}{|c|c|c|c|c|}
\hline \multicolumn{5}{|c|}{ PARTIAL CORRELATION COEFFICIENTS } \\
\hline Controlling for ... SIZE \\
MO & ROI93 & NP93 & \\
\hline MO & 1.0000 & & & \\
ROI93 & $.3824^{* *}$ & 1.0000 & & \\
NP93 & $.3422^{* *}$ & $.5331^{* *}$ & 1.0000 & \\
ROE93 & $.3800^{* *}$ & $.7660^{* *}$ & $.7088^{* *}$ & 1.0000 \\
\hline \multicolumn{6}{|c}{ * Signif. Lev 0.05 } & ** Signif Lev 0.01 (1-tailed) \\
\hline
\end{tabular}

In the light of these results we may conclude that there is a positive relationship between $\mathrm{MO}$ and business results as measured.

To give our analysis more depth, analysis of regression was also carried out. Factors included as determining business results were $\mathrm{MO}$, the positive effect of company size and degree of concern in the company to control costs.

In a highly competitive market like that of insurance, a strategy of market orientation does not conflict with a strategy of low costs. As we have seen, the correlation between the two is positive. In support of our decision to include low costs as a variable in analysis of regression, we would cite:

(a) Research by M. Martinez Martinez (1995), who concluded that cost-reduction strategy is one of the major key strategies for Spanish insurance companies.

(b) The results of the analysis of general strategies of Spanish insurance companies (Lado, 1995), which revealed two predominant orientations of companies: orientation towards innovation and orientation towards low costs. Orientation towards innovation is the more closely-linked of the two to $\mathrm{MO}$ - in fact the correlation is so strong that it was left out of the equation.

Table 9 shows the results of regression analysis in which profits and profitability are explained by the variables MO, emphasis on low costs, and size. For regressions explaining net profits and return on equity, the coefficient of the variables MO, low costs and size are all positive. Curiously enough, the coefficient of the size factor is negative in the regression for ROI, but not significantly so. For the rest, all coefficients bear the expected sign and are significant, as are the regressions.

It should be noted that the analysis included observations for all cases. 
Table 9: Regressions of $M O$, low costs and size in measurement on performance No. of cases $=51$

\begin{tabular}{|l|c|c|c|c|c|c|c|c|c|c|}
\hline \multirow{2}{*}{$\begin{array}{l}\text { Perf. } \\
\text { Meas. }\end{array}$} & \multicolumn{2}{|c|}{ Constant } & \multicolumn{2}{c|}{ MO } & \multicolumn{2}{c|}{ Low costs } & \multicolumn{2}{c|}{ Size } & \multirow{2}{*}{ R $^{2}$} & \multirow{2}{*}{ Sig. F } \\
\cline { 2 - 11 } & coeff. & sig. & coeff. & sig. & coeff. & sig. & coeff. & sig. & & \\
\hline ROI93 & -8.44 & 0.003 & 1.15 & 0.013 & 0.45 & 0.132 & -7.93 & 0.929 & 0.22 & 0.008 \\
\hline NP93 & -2.43 & 0.001 & 268.7 & 0.017 & 165.8 & 0.025 & 0.01 & 0.000 & 0.54 & 0.000 \\
\hline ROE93 & -19.82 & 0.012 & 2.93 & 0.020 & 1.68 & 0.040 & 0.01 & 0.029 & 0.32 & 0.000 \\
\hline
\end{tabular}

These results are extremely interesting, particularly in the case of net profit; here, taking into account the three explanatory factors MO, low costs and size, with highly significant coefficients, the regression has a $\mathrm{R}^{2}$ of 0.54 .

\section{Comparison of results Spain-Belgium}

In this point, we compare the results of our study with those obtained in the study realized by Lambin (1995) about the Belgium Insurance Sector.

Table 10: The degree of market orientation in Belgium and Spain

\begin{tabular}{|ll|c|c|}
\hline \multicolumn{2}{|c|}{ M.O. COMPONENT } & Belgium mean $\left(^{*}\right)$ & Spain mean \\
\hline Final customer & Analysis & 4.409 & 5.320 \\
Orientation & Actions & 6.031 & 6.120 \\
\hline Distributor & Analysis & 5.867 & 6.781 \\
Orientation & Actions & 7.040 & 7.044 \\
\hline Competitor & Analysis & 5.561 & 5.869 \\
Orientation & Actions & 5.571 & 5.765 \\
\hline Environment & Analysis & 5.527 & 5.402 \\
Orientation & Actions & 3.339 & 3.987 \\
\hline Interfunctional & 5.994 & 5.824 \\
Coordination & & \\
\hline Global scale of market & 5.482 & 5.814 \\
Orientation & & \\
\hline
\end{tabular}

$\left({ }^{*}\right)$ Source: Lambin 1995.

As we can see in table 10 , the arithmetical mean level of orientation to the market, obtained in both countries, is very similar. In the same way, the results obtained in the arithmetical mean mesures of each of the nine MO components are similar.

We must remember that they are subjectives measures referred to the staff opinion about the degree obtained in each of its scale items. With the comparison of the obtained results in both countries we must consider the mean of the staff perceptions and that those can be affected by cultural actions. 
We can observe in both countries the emphasis of the orientation to the distributor, where the maximum levels are obtained. In the same way, the minimum level of the nine components concern to the actions over the macro-environment.

Great differences do not appear in close term in the degree of the orientation to the market of the spanish and belgium insurance companies; the profiles of the nine components are similar.

Both results obtained in Belgium and Spain, allow us to conclude considering the existence of a positive and significative impact of the orientation to the market in the performance in a long term of the insurance companies.

\section{Conclusions and discussion}

The main object of this research was to analyse Market Orientation, defined as the intensity with which companies analyse, coordinate their functions and direct their activities towards their final customers, their intermediate clients or distributors, their competitors and their environment.

The MO scale was purified following a procedure recommended by Nunnally (1978), whereby each item was allocated to one of the subscales making up the scale. The reliability and validity of the purified scale was then verified. Upon application of the various tests, levels of reliability and validity of measurement of MO were found to be very good. Having assured the suitability of scale as a means of measuring the construct, MO levels were calculated for each company, these levels being the average of the model's nine components. The results were comparable to those reported by Lambin and Rivera in Belgium. The average score for MO was 5.81. In addition, companies were found to lay particular stress on orientation towards distributors.

One important finding was that market orientation correlates with better long-term economic performance of companies. Moreover, the correlations between MO and results indicators were positive and significant irrespective of company size. While it is true that the larger companies tended to exhibit a higher degree of $\mathrm{MO}$, it was not the size factor alone which made for a positive and significant correlation between $\mathrm{MO}$ and results. Regression analysis showed that business results were determined by market orientation combined with emphasis on low costs plus the size factor. We should note that the indicators of results used in the present research were multiple objective measurements of profitability, profits and business performance.

It is important to provide some perspective for any interpretations and generalizations which may be derived from our conclusions. We must bear in mind the limitations of this research. These include the limitations common to all surveys where data are derived from self-assessment of company executives. Precisely because of the risk of perceptual or attitudinal bias, the survey design called for responses from two executives per company. In view of the precautions taken and the resulting MO values, this kind of bias does not appear to have been of any great magnitude. Again, the present findings are for a single sector of business activity and hence can only be extended to other branches of activity to a very limited degree.

Briefly, then, our findings provide further support for the validity, reliability and applicability of the MO scale. Use of the scale shows a positive relationship between MO and objective indicators of profitability and business returns. The results for Spain are similar 
to those reported in Belgium by Lambin and Rivera, which would indicate that the behaviour of insurers with regard to the market is comparable in the general run of European countries.

Despite the limitations pointed out, we believe that this research helps to demonstrate the potential utility of the MO construct and the various scales related to it, for both academic and business purposes.

\section{REFERENCES}

ARMSTRONG, S. and OVERTON, T. (1977), "Estimating Nonresponse Bias in Mail Surveys", Journal of Marketing Research, 14, pp.396-402.

DAY, G. (1992), "Marketing's Contribution to the Strategy Dialogue", Journal of the Academy of Marketing Sciences, 20 (Fall), pp. 323-29.

JAWORSKI, B. and KOHLI, A. (1993), "Market Orientation: Antecedents and Consequences", Journal of Marketing, 57, July, pp.53-70.

KOHLI, A. and JAWORSKI, B. (1990), "Market Orientation: the Construct, Research Propositions, and Managerial Implications", Journal of Marketing, 54, pp. 1-18.

LADO, N. (1995), “Tipos Estratégicos, Orientación al Mercado y Resultados”, DoctoralThesis, Univ. Autónoma de Madrid.

LAMBIN, J.J. (1995), "The Misunderstanding about Marketing, Today, Marketing is too Important to be Left to Sole Markeitng Function. An Empirical Study in the Private Insurance Sector". CEMS Business Review, 1, p. 1

MARTINEZ MARTINEZ, M. A. (1995), "Organization and Strategy in Insurance: Empirical Research into the Sector in Spain”, The Geneva Papers on Risk and Insurance, 20, 74, pp. 84-100.

NARVER, J. and SLATER, S. (1990), "The Effect of a Market Orientation on Business Profitability", Journal of Marketing, Oct., pp. 20-35.

NUNNALLY, J. (1978), "Psychometric Theory" 2nd. edition, New York, McGraw-Hill Book Company.

PETERSON, R. (1994), "A Meta-analysis of Cronbach's Coefficient Alpha”, Journal of Consumer Research, vol. 21, Sept., pp. 381-391.

REUKERT, R. (1992), "Developing a market orientation: An organizational strategy perspective", International Journal of Research in Marketing, 9, pp. 225-245.

RIVERA, J. (1995), "The Market Orientation: Competitive Organizational Strategy", Working Paper 95-60 Business Economic Serie 09, Dec., Universidad Carlos III de Madrid, Spain.

SLATER, S. and NARVER, J. (1994), "Does Competitive Environment Moderate the Market Orientation-Performance Relationship?", Journal of Marketing, Jan., 58, pp. 46-55. 


\section{APPENDIX 1}

A scale of 0 to 10 is used to measure thge degree to which companies adopt and follow behaviour patterns refelcted by the variables comprising the market orientation model. These variables are listed below.

$\begin{array}{lc} & \text { Variable } \\ \text { 1. } & \text { A1 } \\ 2 . & \text { A2 } \\ \text { 3. } & \text { A3 } \\ \text { 4. } & \text { A4 } \\ \text { 5. } & \text { A5 } \\ \text { 6. } & \text { A6 } \\ \text { 7. } & \text { A7 } \\ \text { 8. } & \text { A8 } \\ \text { 9. } & \text { A9 }\end{array}$

ANALYSIS OF FINAL CUSTOMERS:

Description

MEASUREMENT OF DEGREE OFSATISFACTION MONITORING OF EVOLUTION OFCURRENTNEEDS

KNOWLEDGE OF FACTORS INFLUENCING DECISIONTO BUY INTELLIGENCE FOR DETECTION OF NEWSEGMENTS ROLES INVOLVED INTHE DECISIONTO PURCHASE UNDERSTANDING OF CUSTOMERS' PROBLEM MONITORING OF EVOLUTION OF PRODUCTIMAGE CALCULATION OF PROFITABILITY PER CUSTOMER MONITORING OFEVOLUTION OFPREFERENCES

\section{STRATEGIC ACTION ON FINAL CUSTOMERS:}

Variable Description

10. AA10

OFFER SOLUTIONSWELL-SUITEDTO NEEDS

AA11

AA12

AA13

AA14

AA15

AA16

AA17

AA18

AA19

AA20

EXAMINE CONCEPTSTO RESPONDTO FUTURE NEEDS

COMMERCIALIZE INNOVATIVE PRODUCTS

RAPIDITYOFRESPONSETO CHANGING NEEDS

RAPIDE RESPONSETO CUSTOMER COMPLAINTS

OFFER A RANGE OF PRODUCTS SUITEDTOTHE SEGMENT

RESPONSETO QUALITYPROBLEMS

DEVELOPMENTOFMARKETING PLAN

PROPER IMPLEMENTATION OFTHE MARKETING PLAN

EFFORTTO REDUCE NON'MONETARYACQUISITION COSTS

FULL INFORMATIONTO CUSTOMERS

AA21

SPECIFIC COMMUNICATION FOR EACH SEGMENT

ABANDONMENTOF UNPROFITABLE SEGMENTS

ANALYSIS OF DISTRIBUTORS:

Variable Description

23. B1

MEASURES OF DEGREE OF SATISFACTION

MONITORING OFEVOLUTION OFTHEIR NEEDS

AWARENESS OFTHEIR OBJECTIVES

COMPATIBILITYOF MAKTG. STRATEGYW. DISTS' OBJECTIVES

UNDERSTANDING OF PROBLEMS WITH COMMERCIALIZATION MONITORING OF OWN IMAGE

CALCULATION OF PROFITABILITYPER DISTRIBUTOR AWARENESS OF CUSTOMERS' OPINIONS ON DISTRIBUTORS ANALYSIS OF NEW FORMS OF DISTRIBUTION

\section{STRATEGIC ACTION ON DISTRIBUTORS:}

Variable Description

32. BB112

33. BB13

34. BB14

35. BB15

36. $\quad$ BB17

37. BB20

38. $\quad$ BB22

COMMITMENTTO DISTRIBUTORS BYEXECUTIVE STAFF
TREATMENTOF BROKERS LIKE CUSTOMERS
COMPLETE INFORMATION ON STRATEGY
TRAINING OF DISTRIBUTORSTO IMPROVE SERVICE
CONSULTATION OF DISTRIBUTORS' OPINION ON NEWPROD.
MODIFICATION OF PROD. ATTRIBUTESTO DISTRIBUTOR NEEDS
RAPID ACTION IN RESPONSETO COMPLAINTS

